\title{
The Effectiveness and Value of Oral Immunotherapy and Viaskin Peanut for Peanut Allergy
}

\section{A Summary from the Institute for Clinical and Economic Review's Califormia Technology Assessment Forum}

\author{
Jeffrey A. Tice, MD; Gregory F. Guzauskas, MSPH, PhD; Ryan N. Hansen, PhD, PharmD; \\ Serina Herron-Smith; Celia Segel, MPP; Judith M. E. Walsh, MD, MPH; and Steven D. Pearson, MD, MSc
}

$\mathrm{P}$ eanut is a common childhood allergen in the United States. According to recent estimates, approximately $1.4 \%-4.5 \%$ of U.S. children suffer from peanut allergy.,2 The economic cost of food allergies in the United States is estimated at $\$ 24.8$ billion per year, of which only $\$ 4.3$ billion are direct medical costs. ${ }^{3}$ Nonmedical costs accounted for $\$ 20.5$ billion and included out-of-pocket medical costs, the costs of special foods, and lost caregiver productivity.

The primary approach to managing food allergies is to avoid the food. Research has focused on desensitizing patients by exposing them to increasing amounts of the food, ${ }^{4}$ but no therapies were approved by the U.S. Food and Drug Administration (FDA) at the time of the review by the Institute for Clinical and Economic Review (ICER). The goal of desensitization is to decrease the likelihood that patients will react to an accidental exposure to peanut protein. However, desensitization does not imply tolerance-the ability to eat any amount of food containing peanuts without risk of a serious reaction.

This evidence review examines the effectiveness and value of 2 technologies to desensitize patients with peanut allergy that are expected to be approved by the FDA: AR101, a form of oral immunotherapy (OIT), and Viaskin Peanut, as well as noncommercialized OIT for peanut allergy. ${ }^{5}$

AR101 (Palforzia, Aimmune Therapeutics) is peanut flour produced using Good Manufacturing Practices. ${ }^{6}$ The peanut flour is mixed into pudding, applesauce, or other foods. The dose is gradually increased every 2 weeks to a goal dose of $300 \mathrm{mg}$ daily. A health care professional must observe the patient during the initial dose and each subsequent increase in dose (minimum of 12 total visits). Therapy must be continued indefinitely to maintain desensitization.

Viaskin Peanut (DBV Technologies) is a patch applied daily to the upper back (rotating the location) that delivers $250 \mathrm{mcg}$ of peanut antigen for desensitization treatment. ${ }^{7}$ The first patch is placed under the supervision of a medical professional, but subsequent patches can be applied at home. The patch is worn 6 hours a day for 1 week, then 12 hours a day for another week, and then 24 hours a day from then on. Therapy must be continued indefinitely to maintain desensitization.

J Manag Care Spec Pharm. 2020;26(5):620-23

Copyright $\odot 2020$, Academy of Managed Care Pharmacy. All rights reserved.
ICER conducted a review of AR101, Viaskin Peanut, and OIT In this article, we summarize the systematic literature review and meta-analysis of the clinical effectiveness of the drugs, the cost-effectiveness analysis, and the policy discussion with key stakeholders regarding the overall value of these therapies held at a public meeting of the California Technology Assessment Forum (CTAF) on June 11, 2019. The detailed report is available on the ICER website at https://icer-review.org/material/ peanut-allergy-final-evidence-report-and-meeting-summary/.

\section{Summary of Findings}

\section{Clinical Effectiveness}

We compared the clinical effectiveness of AR101 and Viaskin Peanut to standard of care, which is strict avoidance of peanuts. We also reviewed other forms of OIT, which are offered by some allergists but have not received FDA approval. The primary clinical benefit was desensitization, which was defined differently in each of the trials. The primary harms were system allergic reactions, use of epinephrine, and adverse events leading to discontinuation of therapy.

There were no head-to-head randomized or observational trials comparing the therapies. Table 1 summarizes the pivotal trials of the 2 therapies that were submitted to the FDA. ${ }^{6,7}$ Several important differences should be highlighted. The PALISADE trial of AR101 included older patients (aged 12-17 years) who are less likely to respond to desensitization therapy. The PALISADE trial also enrolled participants with a lowereliciting dose ( $\leq 100 \mathrm{mg}$ vs. $300 \mathrm{mg}$ ), suggesting that their allergy was more severe. The primary outcome in both phase 3 trials was a double-blind placebo-controlled food challenge to evaluate the effectiveness of immunotherapy. However, despite consensus guidelines to assess desensitization, ${ }^{8}$ the 2 trials used different protocols and doses to define desensitization. The PALISADE trial defined desensitization as tolerating $600 \mathrm{mg}$ or higher of peanut protein. The PEPITES trial defined desensitization as tolerating $100 \mathrm{mg}$ for patients enrolled with reactions at $<100 \mathrm{mg}$ and $300 \mathrm{mg}$ enrolled with reactions at 300 mg. Thus, the PALISADE trial of AR101 enrolled participants who were sensitive to lower doses of peanut protein and had a primary outcome that was more difficult to achieve.

The primary benefit documented in both trials was desensitization. In the PALISADE trial, a greater percentage of 
participants randomized to AR101 met the definition of desensitization compared with those randomized to placebo $(67.2 \%$ vs. $4.0 \%, P<0.001) .{ }^{6}$ In the PEPITES trial, the primary outcome required that the lower bound of the $95 \%$ confidence interval (CI) for the difference between the 2 groups be greater than $15 \%$. In the trial, the observed difference was $21.7 \%$ (95\% $\mathrm{CI}=12.4 \%-29.8 \%)^{7}{ }^{7}$ Since the lower bound (12.4\%) was less than $15 \%$, the trial did not meet its primary outcome.

For both AR101 and Viaskin Peanut, patients randomized to active therapy experienced more systemic allergic reactions and used epinephrine more often than patients in the placebo group, which are the outcomes that desensitization should prevent. Short-term increases in these key outcomes are expected, but desensitization should reduce these events over the long term. Reductions in systemic reactions and epinephrine use were not observed during these 1-year trials or in open-label extension studies. There is no evidence demonstrating a reduction in these events with longer therapy.

A systematic review and meta-analysis of 12 randomized trials of OIT reported that a higher proportion of patients achieved desensitization (odds ratio $[\mathrm{OR}]=12.4$, 95\% CI $=6.8$ 22.6). ${ }^{9}$ However, there were significant increases in the risk for anaphylaxis (OR=3.1, 95\% CI=1.8-5.6); epinephrine use $(\mathrm{OR}=2.2,95 \% \mathrm{CI}=1.3-3.8)$; and serious adverse events $(\mathrm{OR}=1.9,95 \% \mathrm{CI}=1.0-3.7)$. These findings were consistent during the buildup and maintenance phases through a maximum follow-up of 5.8 years, although median follow-up was only 1.0 years. Among the 3 studies that assessed quality of life, there were no significant differences between the OIT and placebo groups. The systematic review concluded that high certainty evidence demonstrates that OIT considerably increases allergic and anaphylactic reactions for at least the first year despite effective desensitization without evidence of long-term benefits.

\section{Limitations of the Clinical Evidence for Long-Term Benefit}

Given the potential need for lifelong treatment and the relatively short duration of the trials of AR101 and Viaskin Peanut (1 year), there remains considerable uncertainty about the longterm outcomes for AR101 and Viaskin Peanut. There is hope that the rates of systemic allergic reactions, epinephrine use, and reactions to accidental exposure will decrease with continued therapy, but this has not been demonstrated. The need for longterm therapy also raises concerns about adherence to treatment, particularly during adolescence and young adulthood, which could increase the incidence of severe reactions.

\section{Long-Term Cost-Effectiveness}

We estimated the lifetime cost-effectiveness of the 2 peanut allergy immunotherapies from a U.S. health care sector perspective using a Markov model. The cost-effectiveness model included 2 separate comparisons: (1) AR101 oral immunotherapy plus avoidance compared with avoidance alone, and

\begin{tabular}{|c|c|c|}
\hline & AR101 & Viaskin Peanut \\
\hline Key study & PALISADE & PEPITES \\
\hline Age & 4-17 years & $4-11$ years \\
\hline Peanut sensitivity & $\mathrm{ED} \leq 100 \mathrm{mg}$ & $\mathrm{ED} \leq 300 \mathrm{mg}$ \\
\hline Median baseline ED & $10 \mathrm{mg}$ & $30 \mathrm{mg}$ \\
\hline $\begin{array}{l}\text { Primary outcome in } \\
\text { DBPCFC }\end{array}$ & $\begin{array}{l}\text { Tolerate } 600 \mathrm{mg} \text { peanut } \\
\text { protein at } 1 \text { year }\end{array}$ & $\begin{array}{l}\text { ED } 300 \mathrm{mg} \text { if baseline } \\
\text { ED } \leq 10 \mathrm{mg} ; \text { ED } \\
1,000 \mathrm{mg} \text { if baseline } \\
E D \geq 30 \mathrm{mg} \text { at } 1 \text { year }\end{array}$ \\
\hline Dose escalation & $\begin{array}{l}3 \mathrm{mg} \text { to } 300 \mathrm{mg} \text { daily } \\
\text { with increases every } \\
2 \text { weeks for } 24 \text { weeks }\end{array}$ & $\begin{array}{l}250 \text { mcg patch worn } \\
\text { for } 3 \text { hours day } 1,6 \\
\text { hours week } 1,12 \text { hours } \\
\text { week } 2 \text {, and } 24 \text { hours } \\
\text { thereafter }\end{array}$ \\
\hline Maintenance dose & $\begin{array}{l}300 \text { mg orally } \\
\text { every day }\end{array}$ & $\begin{array}{l}250 \text { mcg by patch } \\
\text { every day }\end{array}$ \\
\hline Clinic visits & Every dose escalation & Day 1 only \\
\hline $\begin{array}{l}\text { Met primary outcome, } \\
\text { active vs. placebo }\end{array}$ & $\begin{array}{l}67.2 \% \text { vs. } 4.0 \% \\
P<0.001\end{array}$ & Not met \\
\hline Quality of life & NR & NR \\
\hline $\begin{array}{l}\text { Overall withdrawal rate, } \\
\text { active vs. placebo }\end{array}$ & $21.0 \%$ vs. $7.3 \%, P=\mathrm{NR}$ & $10.5 \%$ vs. $9.3 \%, P=\mathrm{NR}$ \\
\hline $\begin{array}{l}\text { Systemic allergic } \\
\text { reactions vs. placebo }\end{array}$ & $14.2 \%$ vs. $3.4 \%, P=\mathrm{NR}$ & $\begin{array}{l}3.8 \% \text { related to Viaskin } \\
\text { Peanut vs. } 0 \%, P=\text { NR }\end{array}$ \\
\hline $\begin{array}{l}\text { Use of epinephrine vs. } \\
\text { placebo }\end{array}$ & $14 \%$ vs. $6.5 \%, P=\mathrm{NR}$ & $9.2 \%$ vs. $3.4 \%, P=\mathrm{NR}$ \\
\hline $\begin{array}{l}\text { Severe or serious AE vs. } \\
\text { placebo }\end{array}$ & $5.6 \%$ vs. $1.6 \%, P=\mathrm{NR}$ & $4.7 \%$ vs. $0.8 \%, P=\mathrm{NR}$ \\
\hline \multicolumn{3}{|c|}{$\begin{array}{l}A E=\text { adverse event } ; D B P C F C=\text { double-blind }, \text { placebo-controlled food challenge; } \\
E D=\text { eliciting dose; } N R=\text { not reported. }\end{array}$} \\
\hline
\end{tabular}

(2) Viaskin Peanut plus avoidance compared with avoidance alone. Survival, quality-adjusted survival, serious adverse events (anaphylaxis), and health care costs were summarized over a lifetime time horizon for each treatment option. Full details on ICER's cost-effectiveness analysis and model are available on ICER's website at https://icer-review.org/material/ peanut-allergy-final-evidence-report-and-meeting-summary/.

The costs of immunotherapy with AR101 and Viaskin Peanut were unknown at the time of the public meeting. Based on analyst estimates, we assumed placeholder costs of $\$ 4,200$ per year for AR101 and $\$ 6,500$ per year for Viaskin Peanut. ${ }^{10}$

Trial-reported quality of life outcomes have not yet been published. Health state utilities were derived from the only study in the food allergy literature that included a preferenceweighted measure. The estimates of utility were derived using parent-reported (for children) and adolescent-reported EuroQol-5-Dimension responses. ${ }^{11}$ We assumed that participants in the peanut desensitized health state had an improvement in utility that was $60 \%$ of the difference between utilities for the untreated with peanut sensitivity and peanut-tolerant health states. This assumed that benefit is the source of all of the QALY gains in the model. 


\begin{tabular}{|c|c|c|}
\hline TABLE & \multicolumn{2}{|c|}{$\begin{array}{l}\text { Health Care Sector Cost-Effectiveness } \\
\text { Results for Peanut Desensitization } \\
\text { Therapies }\end{array}$} \\
\hline & Annual Price, $\$$ a & Cost per QALY (95\% CR), \$ \\
\hline AR101 & 4,200 & $(52,000-195,000)$ \\
\hline Viaskin Peanut & 6,500 & $216,000 \quad(126,000-491,000)$ \\
\hline \multicolumn{3}{|c|}{$\begin{array}{l}\text { aPlaceholder prices based on analyst estimates for ICER public meeting. Aimmune } \\
\text { stated that it expects the first } 6 \text { months of treatment with AR101 (Palforzia) to cos } \\
\$ 5,000-\$ 10,000 \text { and } \$ 300-\$ 400 \text { a month after that. } \\
C R=\text { credible range; ICER =Institute for Clinical and Economic Review; } \\
\text { QALY=quality-adjusted life-year. }\end{array}$} \\
\hline
\end{tabular}

The economic model estimated that the incremental costeffectiveness ratios for the 2 therapies ranged from $\$ 88,000$ (95\% credible range $[C R]=\$ 52,000-\$ 195,000)$ per quality-adjusted life-year (QALY) for AR101 to $\$ 216,000$ (95\% $\mathrm{CR}=\$ 126,000-\$ 491,000)$ per QALY for Viaskin Peanut (Table 2). In one-way sensitivity analyses, the results were most sensitive to the utilities associated with peanut sensitivity and peanut desensitization, the cost of immunotherapy, and results of the exit food challenge.

\section{Limitations of the Cost-Effectiveness Model}

Long-term clinical evidence on immunotherapy was not available, and the short-term data suggested greater harm than benefit. The effect of peanut allergy on preference-weighted healthrelated quality of life is also not well characterized. The economic model used preference-weighted utility estimates from a convenience sample of Swedish children with food allergies compared with children without food allergies, so the effect of immunotherapy on QALYs may be inaccurate. Improvement in health-related quality of life (utility) for the desensitized health state were crucial for estimating the overall benefit of the immunotherapies, but there are no data supporting improvements in utilities using the 2 novel therapies or OIT.

\section{Policy Discussion}

The ICER report on immunotherapy for peanut allergy was the subject of a CTAF meeting on June 11, 2019. Following discussion, the CTAF panel members voted that the evidence was not adequate to demonstrate the superiority of AR101 to standard of care (4-12) and that there was not adequate evidence to demonstrate the superiority of Viaskin Peanut to standard of care (4-12). Furthermore, they voted that the evidence was not adequate to distinguish between AR101 and Viaskin Peanut (0-16). Because there was not adequate evidence to demonstrate clinical benefit, no votes were taken on value.

The CTAF panel voted on "other potential benefits" and "contextual considerations" as part of a process to signal to policymakers whether there are important considerations

\section{TABLE 3 Other Benefits or Disadvantages}

Does desensitization therapy for children with peanut allergy offer one or more of the following potential other benefits or disadvantages compared with strict avoidance of peanut protein?

\begin{tabular}{l|c|c}
\hline \multicolumn{1}{c|}{ Potential Other Benefits } & $\begin{array}{c}\text { Viaskin } \\
\text { Votes }\end{array}$ & $\begin{array}{c}\text { AR101 } \\
\text { Votes }\end{array}$ \\
\hline $\begin{array}{l}\text { This intervention will reduce important } \\
\text { health disparities across racial, ethnic, gender, } \\
\text { socioeconomic, or regional categories. }\end{array}$ & $9 / 16$ & $7 / 16$ \\
\hline $\begin{array}{l}\text { This intervention will significantly reduce } \\
\text { caregiver or broader family burden. }\end{array}$ & $10 / 16$ & $11 / 16$ \\
\hline $\begin{array}{l}\text { This intervention offers a novel mechanism of } \\
\text { action or approach that will allow successful } \\
\text { treatment of many patients for whom other } \\
\text { available treatments have failed. }\end{array}$ & $11 / 16$ & $5 / 16$ \\
$\begin{array}{l}\text { This intervention will have a significant effect } \\
\text { on improving return to work and/or overall } \\
\text { productivity. }\end{array}$ & $9 / 16$ & $8 / 16$ \\
$\begin{array}{l}\text { Other important benefits or disadvantages that } \\
\text { should have an important role in judgments of the } \\
\text { value of this intervention. }\end{array}$ & $12 / 16$ & $10 / 16$ \\
\hline
\end{tabular}

when making judgments about long-term value for money not adequately captured in analyses of clinical and/or costeffectiveness. The results of these votes are shown in Tables 3 and 4 . The most important other benefit was the potential to significantly reduce family and caregiver burden. The most important contextual consideration was the considerable uncertainty about the long-term benefits and harms.

The policy roundtable discussion explored how best to translate the evidence and broader perspectives discussed into clinical practice and into pricing and insurance coverage policies. The full set of policy recommendations can be found in the Final Evidence Report on the ICER website: https:// icer-review.org/material/peanut-allergy-final-evidence-reportand-meeting-summary/. Several key policy recommendations are described below:

- Manufacturers should pursue further evidence development to provide greater certainty about the long-term safety and effectiveness of desensitization therapies. Evidence should not rely on short-term surrogate outcome measures such as desensitization.

- Prescribing peanut desensitization therapies should be restricted to specialists (allergy and immunology specialists), or for those patients with inadequate access to allergists, by primary care physicians only in consultation with a specialist.

- Payers may consider limiting coverage for initiation of desensitization treatment to patients between the ages of 4-17 years who represent the population studied to date.

- Payers should not stop coverage at age 18 for patients who have been on continuous desensitization therapy. 


\section{TABLE 4 Contextual Considerations}

Are any of the following contextual considerations important in assessing the long-term value for money of desensitization therapy compared with strict avoidance of peanut protein?

\begin{tabular}{l|c|c}
\hline \multicolumn{1}{c|}{ Potential Other Contextual Considerations } & $\begin{array}{c}\text { Viaskin } \\
\text { Votes }\end{array}$ & $\begin{array}{c}\text { AR101 } \\
\text { Votes }\end{array}$ \\
\hline $\begin{array}{l}\text { This intervention is intended for the care of } \\
\text { individuals with a condition of particularly high } \\
\text { severity in terms of effect on length of life and/or } \\
\text { quality of life. }\end{array}$ & $9 / 15$ & $8 / 15$ \\
\hline $\begin{array}{l}\text { Compared with strict avoidance, there is } \\
\text { significant uncertainty about the long-term risk of } \\
\text { serious side effects of this intervention. }\end{array}$ & $13 / 15$ & $13 / 15$ \\
\hline $\begin{array}{l}\text { Compared with strict avoidance, there is } \\
\text { significant uncertainty about the magnitude } \\
\text { or durability of the long-term benefits of this } \\
\text { intervention. }\end{array}$ & $13 / 15$ & $13 / 15$ \\
$\begin{array}{l}\text { There are additional contextual considerations that } \\
\text { should have an important role in judgments of the } \\
\text { value of this intervention. }\end{array}$ & $4 / 15$ & $4 / 15$ \\
\hline
\end{tabular}

\section{Conclusions}

Both therapies led to higher rates of desensitization to peanut protein in a double-blind food challenge after 1 year of therapy. However, there were higher rates of serious adverse events, systemic allergic reactions, and greater use of epinephrine in the active treatment arm for both therapies compared with placebo treatment. These outcomes should have decreased with effective therapy but did not during 1 year of treatment. In addition, no improvements in quality of life or reductions in anxiety were reported.

\section{Authors}

JEFFREY A. TICE, MD, and JUDITH M. E. WALSH, MD, MPH, University of California, San Francisco. GREGORY F. GUZAUSKAS, MSPH, PhD, and RYAN N. HANSEN, PhD, PharmD, The Comparative Health Outcomes, Policy and Economics (CHOICE) Institute, Department of Pharmacy, University of Washington, Seattle. SERINA HERRON-SMITH; CELIA SEGEL, MPP; and STEVEN D. PEARSON, MD, MSc, Institute for Clinical and Economic Review, Boston, Massachusetts.

AUTHOR CORRESPONDENCE: Jeffrey A. Tice, MD, University of California, San Francisco, 1545 Divisadero St., San Francisco, CA 94115.E-mail:Jeff.Tice@ucsf.edu.

\section{DISCLOSURES}

Funding for this summary was contributed by Arnold Ventures, Commonwealth Fund, California Health Care Foundation, National Institute for Health Care Management (NIHCM), New England States Consortium Systems Organization, Blue Cross Blue Shield of Massachusetts, Harvard Pilgrim Health Care, Kaiser Foundation Health Plan, and Partners HealthCare to the Institute for Clinical and Economic Review (ICER), an independent organization that evaluates the evidence on the value of health care interventions.

ICER's annual policy summit is supported by dues from Aetna, America's Health Insurance Plans, Anthem, Allergan, Alnylam, AstraZeneca Biogen, Blue Shield of CA, Cambia Health Services, CVS, Editas, Express Scripts, Genentech/Roche, GlaxoSmithKline, Harvard Pilgrim, Health Care Service Corporation, Health Partners, Johnson \& Johnson (Janssen), Kaiser Permanente, LEO Pharma, Mallinckrodt, Merck, Novartis, National Pharmaceutical Council, Premera, Prime Therapeutics, Regeneron, Sanofi, Spark Therapeutics, and United Healthcare.

Herron-Smith and Pearson are employed by ICER, which has a contract with the University of California, San Francisco, to perform work for these analyses. Segal was employed by ICER at the time of this review. Tice and Walsh are employed by the University of California, San Francisco. Gazauskas and Hansen have nothing to disclose.

\section{ACKNOWLEDGMENTS}

The authors thank Rick Chapman, PhD, MS; Emily Tsiao, PharmD; Remziye Zaim, MSc, MS; Laura Cianciolo; and Noemi Fluetsch, MPH, for their contributions to ICER's CTAF report on immunotherapy for peanut allergy.

\section{REFERENCES}

1. Gupta RS, Warren CM, Smith BM, et al. The public health impact of parent-reported childhood food allergies in the United States. Pediatrics 2018:142(6):e20181235

2. Bunyavanich S, Rifas-Shiman SL, Platts-Mills TA, et al. Peanut allergy prevalence among school-age children in a US cohort not selected for any disease. J Allergy Clin Immunol. 2014;134(3):753-55.

3. Gupta R, Holdford D, Bilaver L, Dyer A, Holl JL, Meltzer D. The economic impact of childhood food allergy in the United States. JAMA Pediatr. 2013; 167(11):1026-31

4. Jones SM, Burks AW. Food allergy. N Engl J Med. 2017;377(23):2294-95.

5. Nurmatov U, Venderbosch I, Devereux G, Simons FE, Sheikh A. Allergenspecific oral immunotherapy for peanut allergy. Cochrane Database Syst Rev. 2012(9):Cd009014

6. Vickery BP, Vereda A, Casale TB, et al. AR101 oral immunotherapy for peanut allergy. N Engl J Med. 2018;379(21):1991-2001.

7. Fleischer DM, Greenhawt M, Sussman G, et al. Effect of epicutaneous immunotherapy vs placebo on reaction to peanut protein ingestion among children with peanut allergy: the PEPITES Randomized Clinical Trial. JAMA. 2019;321(10):946-55.

8. Sampson HA, Gerth van Wijk R, Bindslev-Jensen C, et al. Standardizing double-blind, placebo-controlled oral food challenges: American Academy of Allergy, Asthma \& Immunology-European Academy of Allergy and Clinical Immunology PRACTALL consensus report. J Allergy Clin Immunol. 2012;130(6):1260-74

9. Chu DK, Wood RA, French S, et al. Oral immunotherapy for peanut allergy (PACE): a systematic review and meta-analysis of efficacy and safety. Lancet. 2019;393(10187):2222-32.

10. Lutrha S. Will I always face the threat of a peanut-laden kiss of death? Kaiser Health News. January 8, 2019. Available at: https://khn.org/news/ will-i-always-face-the-threat-of-a-peanut-laden-kiss-of-death/. Accessed April 1, 2020

11. Protudjer JL, Jansson SA, Ostblom E, et al. Health-related quality of life in children with objectively diagnosed staple food allergy assessed with a disease-specific questionnaire. Acta Paediatr. 2015;104(10):1047-54. 